\title{
AVALIAÇÃO DOS COMPOSTOS FENÓLICOS E DA CAPACIDADE ANTIOXIDANTE DE INGREDIENTES PARA ELABORAÇÃO DE GELEIAS DE ERVA-MATE (ILLEX PARAGUARIENSIS ST-HIL) COM GENGIBRE (ZINGIBER OFFICINALE)
}

\author{
J. P. Fortes ${ }^{1}$; C. O. Santos ${ }^{1}$; M. L. R. Silveira ${ }^{1}$; N. S. P. S. Richards ${ }^{1}$; C. K. Sautter ${ }^{1}$ \\ ${ }^{1}$ Universidade Federal de Santa Maria, Departamento de Tecnologia e Ciência de Alimentos. \\ E-mail para contato: clarissa_obem@hotmail.com
}

\begin{abstract}
RESUMO - Ultimamente estudam-se as ervas aromáticas e especiarias para tratamento e prevenção de doenças, tornando o uso destas em alimentos uma fonte importante destes benefícios. A erva-mate é uma espécie nativa da Argentina, Brasil, Uruguai e Paraguai com papel socioeconômico e cultural. Apresenta compostos bioativos como fenólicos que são antioxidantes e metilxantinas (cafeína, teobromina e teofilina) com ação estimulante. O gengibre tem ação farmacológica, sendo os maiores benefícios atribuídos à solução de distúrbios gastrointestinais. O objetivo deste estudo foi avaliar o teor de compostos fenólicos e capacidade antioxidante de extratos aquosos de matérias-primas para elaboração de geleias de erva-mate com gengibre. $\mathrm{O}$ delineamento experimental foi inteiramente casualizado com nove tratamentos e três repetições. Na formulação dos extratos utilizou-se infusão aquosa de erva-mate (3\%), gengibre em pó $(0,1$ e $0,4 \%)$ e açúcar (60 e 80\%). Determinaramse compostos fenólicos por Folin Ciocalteu e a capacidade antioxidante por DPPH•. Os extratos de erva-mate elaborados com $60 \%$ de açúcar e 0,1 e $0,4 \%$ de gengibre demonstraram elevados teores de compostos fenólicos $(838,9 \pm 48,3$ e 785,6 $658,0 \mathrm{mg}$ EAG $\left.\mathrm{L}^{-1}\right)$. Os extratos apenas com gengibre $(0,1$ e $0,4 \%)$ apresentam baixo teor de fenólicos, no entanto apresentaram alta capacidade antioxidante, com $\mathrm{EC}_{50}$ de

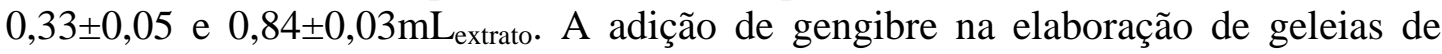
erva-mate contribui para a capacidade antioxidante.
\end{abstract}

\section{INTRODUÇÃO}

A erva-mate (Ilex paraguariensis St. - Hil) pertence à família Aquifoliaceae e é uma espécie nativa das regiões temperadas e subtropicais da América do Sul, cultivada principalmente na Argentina, Paraguai e Brasil, sendo neste amplamente difundida nos estados da região sul (ESMELINDRO et al., 2002). A erva-mate possui inúmeras aplicações, sendo o chimarrão e os chás os produtos mais difundidos, embora possa ser utilizada como ingrediente na elaboração de refrigerantes, sucos, cervejas e vinhos, corante e conservante natural de alimentos e em sorvetes, 
balas, gomas, bombons e caramelos (CORRÊA et al., 1999). As substâncias bioativas que têm despertado maior interesse em pesquisas com a erva-mate são os compostos fenólicos e a cafeína, sendo os principais compostos fenólicos encontrados na erva-mate o ácido cafeíco, a rutina e os derivados dos ácidos clorogênicos com propriedades antioxidantes (PARANÁ, 2000).

Os compostos fenólicos e metilxantinas são produtos naturais, conhecidos como metabólitos secundários produzidos pelos vegetais, apresentando funções ecológicas importantes como proteção contra herbívoros e patógenos (DUTRA, 2009). Por muito tempo as metilxantinas foram consideradas os principais compostos de interesse encontrados na erva-mate, sob o ponto de vista farmacológico e terapêutico, sendo a cafeína um dos constituintes mais estudados (ESMELINDRO et al., 2002). Atualmente, os compostos fenólicos são os constituintes de maior interesse, por apresentarem propriedades benéficas à saúde, atuando como antioxidantes naturais (BRAVO et al., 2007).

O gengibre (Zingiber officinale) é uma das especiarias mais importantes e valorizadas no mundo, sendo uma planta de alto potencial terapêutico em diversas patologias. É uma planta herbácea, da família das Zingiberacea, nativa da Índia, não apresenta raízes, e sim, numerosos rizomas, dos quais são extraídos elementos resinosos bastante aromáticos e de gosto picantes (FILHO e MURTA, 1999). Os principais compostos presentes no gengibre são os óleos essenciais constituindo-se em torno de 1 a $3 \%$, sendo encontrado principalmente o d-canfeno, felandreno, zingibereno, cineol, citral, borneal, gingerol e resina (OLIVEIRA e AKISUE, 2003). Estudos mostram que o gengibre é utilizado no combate de algumas doenças e perturbações da saúde, mas a principal propriedade farmacológica atribuída a essa planta é no combate de problemas gastrointestinais, como náuseas, vômitos, dores de estômago, diarreia, flatulência e úlceras gástricas (CONCEIÇÃO, 2013). Na indústria de alimentos, o principal emprego dos produtos destes rizomas, ocorre como matéria prima em diversas formulações de molhos, sopas, embutidos e em produtos de padaria e confeitaria, como pães, bolos, biscoitos e geleias (LUCIO, 2010).

Considerando as inúmeras aplicações da erva-mate e do gengibre, este estudo tem como objetivo avaliar o teor de compostos fenólicos e a capacidade antioxidante a partir da elaboração de extratos aquosos de geleia de erva-mate com gengibre em diferentes concentrações de sacarose e gengibre em pó.

\section{MATERIAL E MÉTODOS}

\subsection{Delineamento experimental}

O delineamento experimental foi inteiramente casualizado com nove tratamentos com três repetições.

\subsection{Formulações dos extratos de erva-mate e gengibre}


As amostras de erva-mate moída grossa do tipo chimarrão foram cedidas pela Indústria e Comércio de Erva-mate Santiago LTDA (Santiago - RS), embora a matéria-prima para a produção de erva-mate nativa tipo chimarrão seja proveniente do município de Cruz Machado PR. O gengibre em pó utilizado foi adquirido no comércio local do município de Santa Maria RS.

Realizou-se uma infusão aquosa da erva-mate moída grossa tipo chimarrão $\left(30 \mathrm{~g} \mathrm{~L}^{-1}\right)$, mantida em ebulição por 3 minutos e após filtrada em algodão. Com os ingredientes utilizados para a elaboração de geleia de erva-mate condimentada com gengibre, foram elaborados nove extratos aquosos para avaliar o teor dos compostos fenólicos e da capacidade antioxidante, além do possível interferente açúcar, conforme descrito na Tabela 1. Para a elaboração destes extratos, todos os ingredientes foram pesados e adicionados em erlenmeyers de $250 \mathrm{~mL}$, posteriormente adicionou-se água destilada ou infusão de erva-mate, de acordo com o extrato a ser elaborado. A extração ocorreu em sistema de banho-maria fechado com agitação constante, a uma temperatura de $100{ }^{\circ} \mathrm{C}$ durante 15 minutos, simulando as condições de tempo e temperatura necessários para atingir $63^{\circ}$ Brix. Durante este processo, os erlenmeyers permaneceram herméticos com plástico filme. Após o período de cocção, os extratos foram filtrados em papel filtro e acondicionados em frascos de vidro âmbar de $50 \mathrm{~mL}$ e armazenados em temperatura de refrigeração $\left(4{ }^{\circ} \mathrm{C}\right)$ até $\mathrm{o}$ momento das análises.

Tabela 1 - Ingredientes utilizados para a elaboração dos extratos.

Ingredientes

\begin{tabular}{cccccccccc}
\hline & I & II & III & IV & V & VI & VII & VIII & IX \\
\cline { 2 - 8 } Água destilada $(\mathrm{mL})$ & 150 & 150 & - & - & - & - & - & - & - \\
Infusão de erva-mate $(\mathrm{mL})$ & - & - & 150 & 150 & 150 & 150 & 150 & 150 & 150 \\
Açúcar (g) & - & - & - & - & - & 90 & 120 & 90 & 120 \\
Gengibre em pó (mg) & - & - & - & - & - & $(60 \%)$ & $(80 \%)$ & $(60 \%)$ & $(80 \%)$ \\
& $(0,1 \%)$ & $(0,4 \%)$ & - & $(0,1 \%)$ & $(0,4 \%)$ & $(0,1 \%)$ & $(0,1 \%)$ & $(0,4 \%)$ & $(0,4 \%)$ \\
\hline
\end{tabular}

\subsection{Compostos Fenólicos}

A determinação da concentração dos compostos fenólicos nos extratos de erva-mate elaborados foi realizada por meio da reação de oxirredução com reagente de Folin Ciocalteu o qual reage com as hidroxilas presentes nos polifenóis. As leituras em triplicata da absorbância foram realizadas em espectrofotômetro (FEMTO 600 plus ${ }^{\circledR}$ ) em comprimento de onda de 765 nm, conforme o método de Singleton e Rossi (1965). Utilizou-se como padrão o ácido gálico, nas concentrações de $2 ; 4 ; 6 ; 8$ e $10 \mu \mathrm{g} \mathrm{mL}^{-1}$ para construir a curva de calibração $(\mathrm{y}=16,63 \mathrm{x}-$ 
0,$\left.3215 ; R^{2}=0,9877\right)$ e os resultados obtidos foram expressos em equivalentes de ácido gálico (mg L $\left.{ }^{-1} \mathrm{EAG}\right)$.

\subsection{Capacidade Antioxidante}

Para avaliar a capacidade antioxidante dos extratos de erva-mate foi utilizado o método DPPH (2,2-difenil-1-picrilhidrazila), segundo Brand-Williams et al. (1995).

O método DPPH baseia-se na desativação do radical DPPH (2,2-difenil-1-picril-hidrazil) por antioxidantes produzindo um decréscimo da absorbância a $517 \mathrm{~nm}$ que pode ser detectado por espectrofotometria. Os resultados foram expressos em EC50, concentração de amostra capaz de remover $50 \%$ o radical livre $\mathrm{DPPH}\left(\mathrm{EC}_{50} \mathrm{~mL}\right.$ de extrato).

\subsection{Análise estatística}

Todas as análises foram realizadas em triplicata e os resultados foram submetidos à análise de variância (ANOVA), seguido do teste de Tukey $(\mathrm{p}<0,05)$, com auxílio do programa Statistic versão 9.0.

\section{RESULTADOS E DISCUSSÃO}

As análises dos compostos fenólicos e da capacidade antioxidante nos diferentes extratos aquosos com adição de erva-mate, gengibre e açúcar forneceram os resultados apresentados na Tabela 2. Observou-se que os extratos VI e VIII com maior concentração de açúcar (60\%) apresentaram os maiores valores de compostos fenólicos 838,89 e 785,60 mg L $\mathrm{L}^{-1}$ EAG, respectivamente. Este ingrediente pode ter interferido no método, pois os açúcares possuem hidroxilas $(\mathrm{OH})$ que podem ter sido quantificadas como compostos fenólicos, já que reagem com o tungstato de sódio e o molibdênio presente no reagente de Folin Ciocalteu. Assim, os extratos III, IV e V, elaborados somente com infusão de erva-mate; e infusão de erva mate e gengibre em pó nas concentrações 0,1 e $0,4 \%$, respectivamente, apresentaram resultados mais representativos para os compostos fenólicos. 
Tabela 2. Teores de compostos fenólicos e capacidade antioxidante nos extratos elaborados com os ingredientes utilizados para formulações de geleia de erva-mate com gengibre.

\begin{tabular}{crrlrrr}
\hline Extratos & \multicolumn{2}{c}{$\begin{array}{c}\text { Compostos fenólicos } \\
\left(\mathbf{m g ~ L}^{-1} \mathbf{E A G}\right)\end{array}$} & \multicolumn{3}{c}{$\begin{array}{c}\text { DPPH* } \\
\text { (EC }\end{array}$} \\
\hline I & 3,64 & $\pm 0,40$ & $\mathrm{~d}$ & 332,77 & $\pm 54,28$ & $\mathrm{~B}$ \\
II & 8,83 & $\pm 0,83$ & $\mathrm{~d}$ & 841,41 & $\pm 34,25$ & $\mathrm{~B}$ \\
III & 727,95 & $\pm 20,38$ & abc & 2240,01 & $\pm 237,37$ & $\mathrm{~A}$ \\
IV & 666,83 & $\pm 5,20$ & $\mathrm{bc}$ & 1761,99 & $\pm 169,33$ & $\mathrm{~A}$ \\
V & 764,32 & $\pm 21,01$ & ab & 2014,48 & $\pm 61,63$ & $\mathrm{~A}$ \\
VI & 838,89 & $\pm 48,27$ & $\mathrm{a}$ & 2013,24 & $\pm 29,29$ & $\mathrm{~A}$ \\
VII & 619,08 & $\pm 33,94$ & $\mathrm{c}$ & 1983,91 & $\pm 59,23$ & $\mathrm{~A}$ \\
VIII & 785,60 & $\pm 58,01$ & ab & 2344,44 & $\pm 479,09$ & $\mathrm{~A}$ \\
IX & 656,33 & $\pm 89,01$ & $\mathrm{bc}$ & 1833,66 & $\pm 31,43$ & $\mathrm{~A}$ \\
\hline
\end{tabular}

*2,2-difenil-1-picrilhidrazila. Letras minúsculas diferentes na mesma coluna correspondem a diferenças significativas entre os noves tipos de extratos com os ingredientes utilizados para formulações de geleia de erva-mate com gengibre analisados, pelo teste de Tukey $(\mathrm{p}<0,05) \mathrm{n}=3$.

Os extratos aquosos I e II, elaborados com 0,1 e 0,4\% de gengibre em pó apresentaram a maior capacidade antioxidante, pois foram suficientes para inibir $50 \%$ do agente oxidante $2,2-$ difenil-1-picrilhidrazila, diferindo estatisticamente dos demais extratos. No entanto, tal propriedade está correlacionada a outros compostos não fenólicos, pois estes mesmos extratos apresentaram os menores teores de compostos fenólicos (Tabela 2). $\mathrm{O}$ extrato $\mathrm{V}$ com adição de $0,4 \%$ de gengibre em pó e infusão de erva-mate apresentou o terceiro maior valor de atividade antioxidante, apesar de não diferir estaticamente dos demais extratos isso mostra que a erva-mate e o gengibre em pó são fontes de antioxidantes.

Rodrigues e Lira (2013) analisaram o conteúdo de polifenóis em extrato hidroalcoólico com etanol a $70{ }^{\circ} \mathrm{C}$ por sete dias do rizoma do gengibre a $25 \%$ (Zingiber officinale), e encontraram o valor de $1,5 \mathrm{mg} \mathrm{L}^{-1}$ EAG. De acordo com os autores, este valor estaria relacionado com a presença de baixas concentrações de taninos. Comparando-se os resultados obtidos neste estudo com os de Rodrigues e Lira (2013), os extratos analisados com $0,1 \%$ e $0,4 \%$ de gengibre em pó, em meio aquoso extraíram os compostos fenólicos com maior eficiência, apresentando valores de 3,6 a $8,8 \mathrm{mg} \mathrm{L}^{-1}$ EAG. Essa diferença deve-se possivelmente a extração ser em temperatura elevada $\left(100^{\circ} \mathrm{C} / 15 \mathrm{~min}\right.$.).

Poucos trabalhos utilizam erva-mate como matéria prima na produção de alimentos. Berté et al. (2011) obtiveram um extrato aquoso de erva-mate na proporção de 10:100 (m/v) sob aquecimento a $85{ }^{\circ} \mathrm{C}$ durante 30 minutos, e após submetido à secagem em spray dryer para obtenção do extrato de erva-mate em pó com maior concentração de compostos bioativos em relação às folhas. Este extrato foi utilizado para formulações de sete gelatinas funcionais com diferentes tipos e proporções de fibra alimentar e para analisar o teor dos compostos fenólicos (ácido cafeíco, 5-CQA e rutina) em sistema de cromatografia a líquido de alta eficiência (CLAE). Os compostos fenólicos quantificados apresentaram um valor médio de 88,52 mg para $100 \mathrm{~g}$ de sobremesa de gelatina preparada 


\section{CONCLUSÃO}

A geleia de erva-mate é uma inovação tecnológica que pode trazer efeitos benéficos à saúde do consumidor. Os resultados deste estudo evidenciam que o extrato de erva-mate é fonte de compostos fenólicos totais e o gengibre em pó contribui para elevar a capacidade antioxidante da geleia.

\section{AGRADECIMENTO}

Os autores agradecem a Indústria e Comércio de Erva-mate Santiago LTDA pelo fornecimento do material vegetal.

\section{REFERÊNCIAS}

BERTÉ, K. A. S.; IZIDORO, D. R.; DUTRA, F. L. G.; HOFFMANN-RIBANI, R. Desenvolvimento de gelatina funcional de erva-mate. Ciênc. Rural, v.41, p.354-360, 2011.

BRAND-WILIAMS W.; CUVELIER M. E.; BERSET C. Use of a free radical method to evaluate antioxidant activity. Food. Sci. Technol., v. 28, p. 25-30, 1995.

BRAVO, L.; GOYA, L.; LECUMBERRI, E. LC/MS characterization of phenolic constituents of mate (Ilex paraguariensis, St. Hil.) and its antioxidant activity compared to commonly consumed beverages. Food Res. Int., v. 40, p. 393-405, 2007.

CONCEIÇÃ̃, S.F.S.M et al. Efeitos do Gengibre, do Alho e do Funcho na Saúde. Dissertação (Mestrado) - Universidade Fernando Pessoa, Faculdade Ciências da Saúde, Mestre em Ciências Farmacêuticas, p.4-7, Porto, 2013.

CORRÊA S.; KIST B.B.; QUINTANA. Anuário Brasileiro da Erva-Mate. Santa Cruz do Sul, RS: Grupo de Comunicações Gazeta; p.53-55. 1999.

DUTRA, F.L.G. Compostos Fenólicos e Metilxantinas em Erva-Mate Armazenada em Sistemas de Estacionamento Natural e Acelerado. Dissertação (Mestrado) - Universidade Federal do Paraná, Setor de Tecnologia, Curso de Pós-Graduação em Tecnologia de Alimentos. Curitiba, 2009.

ESMELINDRO, M. C.; TONIAZZO, G.; WACZUK, A.; DARIVA, C.; OLIVEIRA, D. Caracterização físico-química da erva-mate: Influência das etapas do processamento industrial. Ciênc. Tecnol. Aliment., Campinas,SP, v. 22, p. 193-204, 2002.

FILHO, A.Z.; MURTA, A.L. Extração do óleo e resinas de gengibre encontrado no litoral paranaense. B. CEPPA, Curitiba, PR: v.17, p.211-228, 1999. 
LUCIO, I. B. Caracterização da inflorescência de gengibre orgânico (Zingiber officinale Roscoe) e sua utilização como alimento. Tese (Doutorado) - Universidade Federal do Paraná, Setor de Tecnologia, Curso de Pós-Graduação em Tecnologia de Alimentos. Curitiba, 2010.

OLIVEIRA, F.; AKISUE, G. Fundamentos de Farmacobotânica. São Paulo: Editora Atheneu, 2003.

PARANÁ. Produtos Alternativos e Desenvolvimento da Tecnologia Industrial na Cadeia Produtiva da Erva-Mate. Câmara Setorial da Cadeia Produtiva da Erva-Mate, Curitiba, PR: Série PADCT III, $\mathrm{n}^{\circ} 1$, p.160, 2000.

RODRIGUES, M. L.; LIRA R. K. Perfil fitoquímico e biológico do extrato hidroalcoólico dos rizomas do gengibre (zingiber officinale roscoe). SaBios: Rev. Saúde e Biol., v.8, p.44-52, 2013.

SINGLETON, V. L.; ROSSI J.A. Colorimetry of phenolics with phosphomolybdic-phosphotungstic acid reagents. Am. J. Enol. Vitic., v. 16, p. 144-58, 1965. 